\title{
Safety Assessment of Auxiliary Lanes in Freeway Interchange Weaving Areas based on Traffic Conflict Technique
}

\author{
Rao Yao ${ }^{1}$, Qiaojun Xiang ${ }^{1}$, Xin Gu ${ }^{1}$, Yifan Guo ${ }^{1}$ and Ting Zhang ${ }^{1}$ \\ ${ }^{1}$ School of Transportation, Southeast University, Si Pai Lou \#2, Nanjing 210096, China
}

\begin{abstract}
Auxiliary lanes can provide an improved weaving environment rather than a forced or direct merge or diverse for vehicles entering and departing freeway weaving segments. Considering China's traffic composition and operational status, this paper proposed safety assessment of auxiliary lanes in freeway interchange weaving areas based on traffic conflict technique in order to estimate its safety impacts and related influential factors considered in design. Based on freeway interchange weaving areas data and actual traffic characteristics, simulation models were built with VISSIM. This paper used Surrogate Safety Assessment Model (SSAM) to calculate conflicts by inputting vehicle trajectories from VISSIM, analysed the influence of ramp spacing, lane number of mainline, traffic volume, weaving ratio and percentage of heavy vehicles on safety performance of auxiliary lanes in freeway weaving areas. Finally, Traffic Conflict Modification Factor was presented to evaluate effectiveness of implementing auxiliary lanes. The paper found the safety impacts and related influential factors of auxiliary lanes. The findings can provide support to effective decision making with regards to constructing future auxiliary lanes in freeway interchange weaving areas.
\end{abstract}

\section{Introduction}

As an important part of freeway, interchange and its operation performance is of great importance to the entire road network. Traffic flow features in weaving areas are much more complicated than other function areas, therefore, weaving areas have a great influence on interchange safety. Auxiliary lane (AL) is a common facility in interchange weaving areas and is often used to improve weaving environment by adding lanes between entrance-and exit-ramp pairs when the ramps are close. There are many standards specifications about AL setting and designing methods: A Policy on Geo metric Design of Highway and Streets (AASHTO Green Book, 2004) [1], Manual on Uniform Traffic Control Devices (MUTCD, 2009) [2], Japan Highway Design Essentials (1991) [3], Design Specification for Highway Alignment (2006) [4] and Guidelines for Design of Highway Grade-separated Intersections [5]. However, the setting methods and geometric design guidelines listed in these specifications are mainly based on capacity analysing and lack detail, which could lead to uncertainty to traffic engineers when considering designing ALs. Besides, a large proportion of AL-related researches focus on the operational impacts of ALs, very few on safety impacts.

As for the researches on safety impacts of ALs, Beverly Kuhn.et al analysed roads setting conditions and traffic crash rates in ramp influential areas and found that implementing ALs in merge and weaving areas can effectively reduce traffic crash and conflicts [6]. According to principles of lane balance, Hongjun Tian took Wang Guantun interchange on Ji Nan-He Ze highway as an example to evaluate impacts of ALs and found that ALs can reduce the interruptions of main line vehicles, make traffic running smoother and safer [7]. Worku Mergia identified crash injury severity influential factors were diver-related, traffic, environmental and geometric design factors. A generalized ordinal logit model and partial proportional odds model were applied to identify the factors that increase the likelihood of one of five levels of injury severity: no injuries, possible/invisible injuries, non-incapacitating injuries, incapacitating injuries, or fatal injuries. It was found that the use of continuous auxiliary lanes between an entrance ramp and an exit ramp tends to increase the like lihood of severe injuries near the diverge areas [8]. Sarhan.et al studied 34 weaving segments in 26 interchanges to investigate the effects of ramp terminal spacing and traffic volumes on safety performance. Some findings were found included: 1) the historical crash records show that the implement of ALs did not improve the safety performances significantly at these sites. 2) Weaving Type A was associated with relatively lower collision frequencies when compared with weaving Type B. 3) the number of collisions will decrease with increasing length of speed-change lane [9]. Richard Glad analysed datasets and found that two-thirds of the rear-ends and one-third of the sideswipe occurred in ALs in weaving areas, although the crashes were mainly attributed to weaving traffic instead of the presence of ALs [10]. Yi Qi.et al presented Traffic Conflict Modification Factor (TCMF) as an indicator to analyse the changes in conflict 
frequency before and after implementing ALs under different conditions by simulation software. It was found that the reduction of traffic conflicts could be especially significant when high weaving volu mes were present [11].

From the literature review, we can conclude that the safety impacts of ALs and related influential factors haven't been studied clearly. Besides, the analysis on safety impacts of ALs are mainly based on historical crash records. Crash records have issues of small simple size, difficulty of obtaining, low data reliability and large time span. What is more, the method of analysing crash records is not available for facilities or managements to be or are being planned. It has been proved that traffic conflict is in correlation with traffic crash and is an effective surrogate measure of evaluating traffic safety. Traffic Conflict Technique (TCT) has the advantages of short periods, large simple size and high data reliability, etc. Safety performance can be evaluated under different conditions by combining TCT with simulation.

Therefore, TCT is applied in this paper to assess safety impacts of ALs in freeway interchange weaving areas. Take the basic setting form of ALs as an example, different influential factors were studied in order to provide detailed guidelines on ALs planning and designing. This paper also provide support to effective decision making with regards to weaving areas geometric design, management and prevention of accidents.

\section{Method}

\subsection{Data collection}

The traffic survey was conducted at a semi-cloverleaf interchange with a typical weaving areas, which is composed of a one-lane mainline and a one-lane ramp (one-lane entrance and one-lane exit with one AL between). (Fig. 1) The width of every lane is $3.75 \mathrm{~m}$. The ramp spacing is about $165 \mathrm{~m}$ and the radius of the ramps is $60 \mathrm{~m}$. Note that the mainline is in fact a collectordistributor road, so the weaving volume was high in this area, satisfying the requirement of sample size.

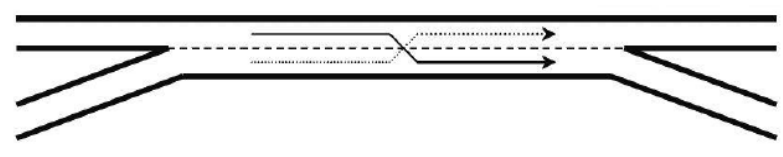

Figure 1. Weaving area in survey

In order to observe and analyse the traffic conflicts clearly, un manned aerial vehic le (UA V) photography was allowed to shoot video in good conditions. High definition of the whole view of the interchange weaving areas can be obtained from the video.To get enough traffic volume and traffic conflicts and eliminate random errors, four times shooting separately in the morning and afternoon. Besides, because of the limitation of battery lasting time, every one time lasts about 15 minutes. Finally two hours high-precision video was obtained. The aerial photo was below. (Fig.2)

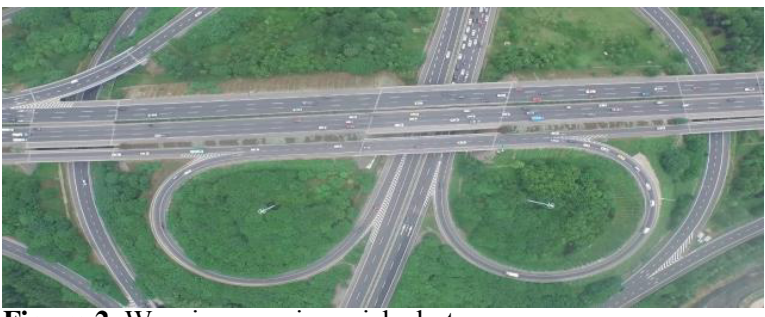

Figure 2. Weaving area in aerial photo

\subsection{VISSIM-based simulation model of the auxiliary lanes}

\subsubsection{Model Assumption}

Specific to the characteristics of the weaving area and the function of the simulation software, some as sumptions are present as below.

- According to Chapter 12 of HCM 2010[12], there is at least one AL in freeway weaving area. It also states that a freeway segment between an on-ramp and an offramp but without an A L should be analysed separately as isolated merge and diverge areas. However, for continuity and simplicity in analysis for the rest of this paper, we assume that a weaving area can be designed with or without ALs.

- Assume that the main line and the ramps are straight, the influence of horizontal curve is neglected. Just consider the geometrical parameters such as length, width of the lane in the simulation experiment.

- The influence of gradient is considered to be 0 .

- The angle between the ramp and mainline is $25^{\circ}$ and the typical auxiliary lanes analysed in this paper is parallel type introduced in HCM 2010.

- The influences of weather conditions and lateral clear width on the traffic flow are neglected.

- Only small cars (Car) and heavy vehicles (HGV) are considered in the discussion.

- Assume that the design speed of the mainline is $80 \mathrm{~km} / \mathrm{h}$ and the ramp is $40 \mathrm{~km} / \mathrm{h}$.

\subsubsection{Parameter Calibration}

Calibration in simulation mainly includes the representative vehicle parameters and three types of driver behaviours models: the car-following model, the lane-changing model and the transverse behaviour model [13]. Refer to the previous related research and take this paper's research object into consideration, parameters are set as follows:

- Representative Vehicle Parameters Calibration

Cars and HGVs are considered in this paper and the calibration of vehicle characteristic parameters include the length, maximum/minimum and expectation of acceleration/deceleration. Specific settings are shown in Table 1.

- The Car-following model

The Wiedemann99 Car-following model was adopted and the specific parameters are shown in Table 2.

- The lane-changing model 
Line-changing is the most significant behavior in weaving areas. Frequent lane changes may lead to disruption and congestion in traffic flow. The lanechanging model parameters include Min.Headway, Lane change Behavior and to slower lane if collision time above. Specific parameters setting are shown in Table3.

- The transverse behavior model

Desired Positon at Free Flow, Min.Lateral Distance and Overtake on same lane are the main parameters in the transverse behaviour model.

- Simulation time period and number of times

Considering the field investigation data, sample size requirement and in order to eliminate the influence of randomness of both traffic conflicts and simulation, every simulation under each different combination of conditions conduct 10 times, every time lasts 4500 s and the average is adopted as the final result.

Table 1 Vehicle Parameters in simulation software

\begin{tabular}{|c|c|c|c|c|c|c|}
\hline \multirow{2}{*}{$\begin{array}{c}\text { Vehicle } \\
\text { Type }\end{array}$} & \multirow{2}{*}{$\begin{array}{c}\text { Length } \\
\text { of } \\
\text { Vehicle } \\
\end{array}$} & $\begin{array}{c}\text { Width } \\
\text { of }\end{array}$ & \multicolumn{2}{|c|}{$\begin{array}{c}\text { Acceleration } \\
\left(\mathbf{m} / \mathbf{s}^{\mathbf{2}}\right)\end{array}$} & \multicolumn{2}{|c|}{$\begin{array}{c}\text { Deceleration } \\
\left(\mathbf{m} / \mathbf{s}^{\mathbf{2}}\right)\end{array}$} \\
\cline { 5 - 7 } & $(\mathbf{m})$ & Max. & Exp. & Max. & Exp. \\
\hline Car & $4.2-4.9$ & 1.5 & 3.5 & 3.1 & 5.0 & 4.6 \\
\hline HGV & $7.0-13.0$ & 2.5 & 2.5 & 2.0 & 4.8 & 4.2 \\
\hline
\end{tabular}

Table 2 Parameters in Wiedemann99 Car-following model

\begin{tabular}{|c|l|c|c|c|c|}
\hline Parameter & Value & Parameter & Value & Parameter & Value \\
\hline $\begin{array}{c}\text { Standstill } \\
\text { distance } \\
(\mathrm{CC} 0)\end{array}$ & $1.50 \mathrm{~m}$ & $\begin{array}{c}\text { Negative } \\
\text { following } \\
\text { thresholds } \\
\text { (CC4) }\end{array}$ & -0.35 & $\begin{array}{c}\text { Standstill } \\
\text { acceleration } \\
\text { (CC8) }\end{array}$ & $3.5 \mathrm{~m} / \mathrm{s}^{2}$ \\
\hline $\begin{array}{c}\text { Headway } \\
\text { time } \\
(\mathrm{CC} 1)\end{array}$ & $1.60 \mathrm{~s}$ & $\begin{array}{c}\text { Positive } \\
\text { following } \\
\text { thresholds } \\
\text { (CC5) }\end{array}$ & 0.35 & $\begin{array}{c}\text { Acceleration } \\
\text { at } 80 \mathrm{~km} / \mathrm{h} \\
\text { (CC9) }\end{array}$ & $1.6 \mathrm{~m} / \mathrm{s}^{2}$ \\
\hline $\begin{array}{c}\text { Following } \\
\text { variation } \\
(\mathrm{CC} 2)\end{array}$ & $3.60 \mathrm{~m}$ & $\begin{array}{c}\text { Speed } \\
\text { dependency } \\
\text { of oscillation } \\
\text { (CC6) }\end{array}$ & 11.44 & $\begin{array}{l}\text { Look Ahead } \\
\text { Distance(m) }\end{array}$ & $0 \sim 200$ \\
\hline $\begin{array}{c}\text { Threshold } \\
\text { of entering } \\
\text { following } \\
(\mathrm{CC} 3)\end{array}$ & -7.67 & $\begin{array}{c}\text { Oscillation } \\
\text { acceleration } \\
\text { (CC7) }\end{array}$ & 0.25 & $\mathrm{~m} / \mathrm{s}^{2}$ & Observed \\
Vehicles & 4 \\
\hline
\end{tabular}

Table 3. Parameters in lane-changing model

\begin{tabular}{|c|c|c|c|c|c|}
\hline \multicolumn{2}{|c|}{ Parameter } & Value & \multicolumn{2}{|c|}{ Parameter } & Value \\
\hline \multirow{2}{*}{$\begin{array}{c}\text { Max. } \\
\text { deceleration }\end{array}$} & own & $\begin{array}{l}-5.86 \\
\mathrm{~m} / \mathrm{s}^{2}\end{array}$ & \multirow{2}{*}{$\begin{array}{l}\text { Accepted } \\
\text { deceleration }\end{array}$} & own & $\begin{array}{l}-1.00 \\
\mathrm{~m} / \mathrm{s}^{2}\end{array}$ \\
\hline & $\begin{array}{l}\text { Trailing } \\
\text { vehicle }\end{array}$ & $\begin{array}{l}-3.00 \\
\mathrm{~m} / \mathrm{s}^{2}\end{array}$ & & $\begin{array}{l}\text { Trailing } \\
\text { vehicle }\end{array}$ & $\begin{array}{l}-0.50 \\
\mathrm{~m} / \mathrm{s}^{2}\end{array}$ \\
\hline \multirow{2}{*}{$\begin{array}{l}-1 \mathrm{~m} / \mathrm{s}^{2} \text { per } \\
\text { distance }\end{array}$} & own & $150 \mathrm{~m}$ & \multicolumn{2}{|c|}{$\begin{array}{l}\text { Waiting time before } \\
\text { diffusion }\end{array}$} & $60.0 \mathrm{~s}$ \\
\hline & $\begin{array}{l}\text { Trailing } \\
\text { vehcle }\end{array}$ & $100 \mathrm{~m}$ & \multicolumn{2}{|c|}{$\begin{array}{l}\text { Min. HeadWay } \\
\text { (front/rear) }\end{array}$} & $0.6 \mathrm{~m}$ \\
\hline \multicolumn{2}{|c|}{$\begin{array}{l}\text { Safety distance } \\
\text { reduction factor }\end{array}$} & 0.60 & \multicolumn{2}{|c|}{$\begin{array}{l}\text { Maximum deceleration } \\
\text { for cooperative braking }\end{array}$} & $\begin{array}{l}-3.50 \\
\mathrm{~m} / \mathrm{s}^{2}\end{array}$ \\
\hline
\end{tabular}

\subsubsection{Model Verification}

We carry out the simulation by setting up a simulation network of a freeway weaving area with an AL and take the practical survey data as input parameters, such as traffic volume, percentage of $\mathrm{HGV}$, etc. Mean travel time and traffic conflict counts are chosen as indicators of simulation test, and mean absolute percentage error is used to calculate the errors. Mean travel time can be obtained by setting time sampler on the roads and traffic conflict counts can be obtained by analyzing the vehicle trajectories through SSAM.

The verification result is shown in TABLE 4. It is shown that the errors of mean travel time and traffic conflict counts are $1.648 \%$ and $9.69 \%$ respectively. So the simulation model is valid.

Table 4. Model verification test results

\begin{tabular}{|c|c|c|c|c|}
\hline \multirow{4}{*}{$\begin{array}{c}\text { Travel } \\
\text { Time } \\
\text { Test }\end{array}$} & Test Group & $\begin{array}{c}\text { Observation } \\
\text { value } \\
(\mathbf{s})\end{array}$ & $\begin{array}{c}\text { Simulation } \\
\text { value } \\
(\mathbf{s})\end{array}$ & $\begin{array}{c}\text { MAPE } \\
\text { \% }\end{array}$ \\
\cline { 2 - 5 } & 1 & 11.2 & 11.4 & 1.786 \\
\cline { 2 - 5 } & 2 & 10.93 & 11 & 0.640 \\
\cline { 2 - 5 } & 3 & 11.3 & 11.2 & 0.885 \\
\cline { 2 - 5 } & 4 & 11.49 & 11.1 & 3.394 \\
\cline { 2 - 5 } & Ave. & 12.39 & 12.2 & 1.533 \\
\hline \multirow{4}{*}{\begin{tabular}{c} 
Tenflict \\
\cline { 2 - 5 }
\end{tabular}} & 1 & 67 & 11.38 & $\mathbf{1 . 6 4 8}$ \\
\cline { 2 - 5 } & 2 & 42 & 37 & 14.93 \\
\cline { 2 - 5 } & 3 & 64 & 58 & 7.14 \\
\cline { 2 - 5 } & 4 & 77 & 68 & 11.69 \\
\cline { 2 - 5 } & Ave. & 68.8 & 62.2 & $\mathbf{9 . 6 9}$ \\
\hline
\end{tabular}

\subsubsection{Simulation Scheme}

This paper's purpose is to evaluate safety impacts of auxiliary lanes in freeway interchange weaving areas. Safety influential factors can be mainly divided into geographic conditions (ramp spacing, lane numbers of ramp, lane numbers of main line, lane width, etc.), traffic conditions (through volume, weaving ratio, ramp-to-ramp volume, percentage of $\mathrm{HGV}$, etc.) and other management conditions.

To avoid complication of processing data and to get representative results at the same time, kinds of combinations of conditions are established in the simulation, the specific conditions of simulation schemes are shown in TABLE5. We can get a total of 72 simu lation scenarios to compare safety conditions with an AL or not.

Table 5. Conditions of traffic simulation.

\begin{tabular}{|c|c|c|c|}
\hline \multirow{2}{*}{ Road Condition } & \multicolumn{2}{|c|}{$\begin{array}{c}\text { Ramp Spacing (m) } \\
L_{s}\end{array}$} & $\begin{array}{l}200,300 \\
\quad 400\end{array}$ \\
\hline & \multicolumn{2}{|c|}{$\begin{array}{c}\text { Lane Number of Mainline } \\
\qquad N\end{array}$} & $1,2,3$ \\
\hline \multirow{3}{*}{$\begin{array}{c}\text { Traffic } \\
\text { Conditions }\end{array}$} & \multirow{3}{*}{$\begin{array}{l}\text { Traffic } \\
\text { Volume }\end{array}$} & $\begin{array}{c}\text { Through Volume } \\
\text { (veh/h/ln) } \\
V_{F F}\end{array}$ & 1000,1400 \\
\hline & & $\begin{array}{c}\text { Weaving Volume } \\
\text { Ratio } \\
R_{w}\end{array}$ & $0.2,0.4$ \\
\hline & & $\begin{array}{c}\text { Ramp-to-Ramp } \\
\text { Volume(veh/h/ln) } \\
V_{R R}\end{array}$ & 10 \\
\hline
\end{tabular}




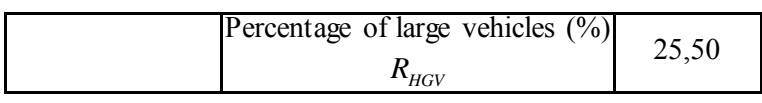

\subsection{Traffic Conflicts Model and Asse ssment Index}

SSAM is used to process data describing the trajectories of vehicles provided in simulation software, VISSIM in this paper. SSAM calculates surrogate measures of safety among every two vehicles and discern conflicts if the interaction satisfies the criteria for conflicts. [14] In this paper, TTC is chosen as the criteria for conflicts and it is defined as the minimum time to collision value observed during the interaction of two vehicles on collision course. In this paper, we use $4 \mathrm{~s}$ as the threshold and if at any time step the TTC is below this value, the interaction is tagged as a conflict [15].

Traffic Conflict Rate is used as assessment index, and we use TCMFs (Traffic Conflict Modification Factor) to analyze the safety impacts of ALs. Similar to the CMFs presented in the AASHTO HSM, the TCMFs were provided for estimating the expected changes of traffic conflict rate at a location after implementing specific geometric treatments associated with an AL. The TCMFs were calculated as follows [11]:

$$
\mathrm{TCMF}=\frac{\text { Traffic } \text { Conflict Rate after Treatment }}{\text { Traffic Conflict Rate before Treatment }} \times 100 \%
$$

If a TCMF value is less than 1.0, it means the treatment may potentially reduce the traffic conflicts and improve the safety performance.

\section{Results}

Decreases in traffic conflict rate are found after implementing an AL by analyzing the statistical results. The safety performance of ALs in weaving areas is related to ramp spacing, lane number of mainline, traffic volume, weaving ratio and percentage of $\mathrm{HGV}$, as shown in Table6 8.

Table 6 TCMFs for weaving areas $(N=1)$

\begin{tabular}{|c|c|c|c|c|c|c|}
\hline \multirow{2}{*}{$\begin{array}{l}L_{s} \\
(\mathbf{m})\end{array}$} & \multicolumn{2}{|c|}{ Traffic Volume } & \multirow[b]{2}{*}{$\begin{array}{l}R_{H G V} \\
(\%)\end{array}$} & \multirow{2}{*}{\begin{tabular}{|c} 
Conflict \\
Rate \\
Before \\
$(\%)$
\end{tabular}} & \multirow{2}{*}{$\begin{array}{l}\text { Conflict } \\
\text { Rate } \\
\text { After } \\
(\%)\end{array}$} & \multirow[b]{2}{*}{ TCMF } \\
\hline & $\begin{array}{c}V_{F F} \\
(\operatorname{veh} / \mathbf{h} / \mathbf{l n})\end{array}$ & $R_{w}$ & & & & \\
\hline \multirow{8}{*}{200} & \multirow{4}{*}{1000} & \multirow{2}{*}{0.2} & 25 & 22.10 & 4.42 & 0.2 \\
\hline & & & 50 & 25.05 & 4.76 & 0.19 \\
\hline & & \multirow{2}{*}{0.4} & 25 & 26.83 & 4.83 & 0.18 \\
\hline & & & 50 & 29.88 & 5.08 & 0.17 \\
\hline & \multirow{4}{*}{1400} & \multirow{2}{*}{0.2} & 25 & 34.27 & 5.14 & 0.15 \\
\hline & & & 50 & 39.00 & 5.46 & 0.14 \\
\hline & & \multirow{2}{*}{0.4} & 25 & 40.07 & 5.61 & 0.14 \\
\hline & & & 50 & 44.08 & 5.73 & 0.13 \\
\hline \multirow{6}{*}{300} & \multirow{4}{*}{1000} & \multirow{2}{*}{0.2} & 25 & 8.07 & 3.55 & 0.44 \\
\hline & & & 50 & 8.53 & 3.67 & 0.43 \\
\hline & & \multirow{2}{*}{0.4} & 25 & 9.21 & 3.87 & 0.42 \\
\hline & & & 50 & 10.63 & 4.25 & 0.40 \\
\hline & \multirow{2}{*}{1400} & \multirow{2}{*}{0.2} & 25 & 11.47 & 4.36 & 0.38 \\
\hline & & & 50 & 12.67 & 4.56 & 0.36 \\
\hline
\end{tabular}

\begin{tabular}{|c|c|c|c|c|c|c|}
\hline & & \multirow{2}{*}{0.4} & 25 & 13.57 & 4.75 & 0.35 \\
\hline & & & 50 & 13.91 & 4.87 & 0.35 \\
\hline \multirow{8}{*}{400} & \multirow{4}{*}{1000} & \multirow{2}{*}{0.2} & 25 & 3.06 & 1.53 & 0.50 \\
\hline & & & 50 & 3.20 & 1.60 & 0.50 \\
\hline & & \multirow{2}{*}{0.4} & 25 & 3.41 & 1.67 & 0.49 \\
\hline & & & 50 & 3.81 & 1.79 & 0.47 \\
\hline & \multirow{4}{*}{1400} & \multirow{2}{*}{0.2} & 25 & 4.00 & 1.84 & 0.46 \\
\hline & & & 50 & 4.40 & 1.98 & 0.45 \\
\hline & & \multirow{2}{*}{0.4} & 25 & 4.77 & 2.05 & 0.43 \\
\hline & & & 50 & 5.05 & 2.12 & 0.42 \\
\hline & & & & & Avera & 0.34 \\
\hline
\end{tabular}

Table 7 TCMFs for weaving areas $(N=2)$

\begin{tabular}{|c|c|c|c|c|c|c|}
\hline \multirow{2}{*}{$\begin{array}{l}L_{s} \\
(\mathbf{m})\end{array}$} & \multicolumn{2}{|c|}{ Traffic Volume } & \multirow{2}{*}{$\begin{array}{l}R_{H G V} \\
(\boldsymbol{\%})\end{array}$} & \multirow{2}{*}{$\begin{array}{c}\text { Conflict } \\
\text { Rate } \\
\text { Before } \\
(\%) \\
\end{array}$} & \multirow{2}{*}{$\begin{array}{c}\text { Conflict } \\
\text { Rate } \\
\text { After } \\
(\%)\end{array}$} & \multirow[b]{2}{*}{ TCMF } \\
\hline & $\begin{array}{c}V_{F F} \\
(\operatorname{veh} / \mathbf{h} / \mathbf{l n}) \\
\end{array}$ & $R_{w}$ & & & & \\
\hline \multirow{8}{*}{200} & \multirow{4}{*}{1000} & \multirow{2}{*}{0.2} & 25 & \begin{tabular}{|l|}
8.91 \\
\end{tabular} & 3.12 & 0.35 \\
\hline & & & 50 & 9.59 & 3.26 & 0.34 \\
\hline & & \multirow{2}{*}{0.4} & 25 & 12.96 & 3.63 & 0.28 \\
\hline & & & 50 & 15.69 & 4.08 & 0.26 \\
\hline & \multirow{4}{*}{1400} & \multirow{2}{*}{0.2} & 25 & 18.43 & 4.24 & 0.23 \\
\hline & & & 50 & 21.33 & 4.48 & 0.21 \\
\hline & & \multirow{2}{*}{0.4} & 25 & 25.61 & 4.61 & 0.18 \\
\hline & & & 50 & 26.44 & 4.76 & 0.18 \\
\hline \multirow{8}{*}{300} & \multirow{4}{*}{1000} & \multirow{2}{*}{0.2} & 25 & 4.36 & 3.01 & 0.69 \\
\hline & & & 50 & 4.72 & 3.07 & 0.65 \\
\hline & & \multirow{2}{*}{0.4} & 25 & 4.92 & 3.10 & 0.63 \\
\hline & & & 50 & 5.43 & 3.31 & 0.61 \\
\hline & \multirow{4}{*}{1400} & \multirow{2}{*}{0.2} & 25 & 6.33 & 3.61 & 0.57 \\
\hline & & & 50 & 6.76 & 3.65 & 0.54 \\
\hline & & \multirow{2}{*}{0.4} & 25 & 7.21 & 3.75 & 0.52 \\
\hline & & & 50 & 8.00 & 3.84 & 0.48 \\
\hline \multirow{8}{*}{400} & \multirow{4}{*}{1000} & \multirow{2}{*}{0.2} & 25 & 1.77 & 1.33 & 0.75 \\
\hline & & & 50 & 2.01 & 1.47 & 0.73 \\
\hline & & \multirow{2}{*}{0.4} & 25 & 2.24 & 1.52 & 0.68 \\
\hline & & & 50 & 2.60 & 1.61 & 0.62 \\
\hline & \multirow{4}{*}{1400} & \multirow{2}{*}{0.2} & 25 & 2.86 & 1.69 & 0.59 \\
\hline & & & 50 & 2.98 & 1.73 & 0.58 \\
\hline & & \multirow{2}{*}{0.4} & 25 & 3.33 & 1.80 & 0.54 \\
\hline & & & 50 & 3.85 & 2.0 & 0.52 \\
\hline & & & & & Average & 0.49 \\
\hline
\end{tabular}

Table 8 TCMFs for weaving areas $(N=3)$

\begin{tabular}{|c|c|c|c|c|c|c|}
\hline \multirow{2}{*}{$\begin{array}{l}L_{s} \\
(\mathbf{m})\end{array}$} & \multicolumn{2}{|c|}{ Traffic Volume } & \multirow[b]{2}{*}{$\begin{array}{r}R_{H G V} \\
(\%)\end{array}$} & \multicolumn{2}{|c|}{\begin{tabular}{|l|l} 
Conflict & Conflict
\end{tabular}} & \multirow[b]{2}{*}{ TCMF } \\
\hline & $\begin{array}{c}V_{F F} \\
(\text { veh/h/ln) }\end{array}$ & $R_{w}$ & & $\begin{array}{l}\text { Rate } \\
\text { Before } \\
(\%)\end{array}$ & $\begin{array}{l}\text { Rate } \\
\text { After } \\
(\%)\end{array}$ & \\
\hline \multirow{8}{*}{200} & \multirow{4}{*}{1000} & \multirow{2}{*}{0.2} & 25 & 5.60 & 2.52 & 0.45 \\
\hline & & & 50 & 6.21 & 2.61 & 0.42 \\
\hline & & \multirow{2}{*}{0.4} & 25 & 6.90 & 2.69 & 0.39 \\
\hline & & & 50 & 7.83 & 2.74 & 0.35 \\
\hline & \multirow{4}{*}{1400} & \multirow{2}{*}{0.2} & 25 & 9.06 & 2.81 & 0.31 \\
\hline & & & 50 & 10.21 & 2.86 & 0.28 \\
\hline & & \multirow{2}{*}{0.4} & 25 & 11.68 & 2.92 & 0.25 \\
\hline & & & 50 & 13.17 & 3.16 & 0.24 \\
\hline \multirow{8}{*}{300} & \multirow{4}{*}{1000} & \multirow{2}{*}{0.2} & 25 & 3.04 & 2.31 & 0.76 \\
\hline & & & 50 & 3.40 & 2.45 & 0.72 \\
\hline & & \multirow{2}{*}{0.4} & 25 & 3.89 & 2.57 & 0.66 \\
\hline & & & 50 & 4.14 & 2.69 & 0.65 \\
\hline & \multirow{4}{*}{1400} & \multirow{2}{*}{0.2} & 25 & 4.54 & 2.77 & 0.61 \\
\hline & & & 50 & 4.80 & 2.83 & 0.59 \\
\hline & & \multirow{2}{*}{0.4} & 25 & 5.18 & 2.90 & 0.56 \\
\hline & & & 50 & 6.10 & 3.11 & 0.51 \\
\hline 400 & 1000 & 0.2 & 25 & 1.54 & 1.28 & 0.83 \\
\hline
\end{tabular}




\begin{tabular}{|c|c|c|c|c|c|c|}
\hline \multirow{3}{*}{} & & 50 & 1.67 & 1.35 & 0.81 \\
\cline { 3 - 6 } & \multirow{3}{*}{0.4} & 25 & 1.95 & 1.48 & 0.76 \\
\cline { 3 - 6 } & & 50 & 2.08 & 1.52 & 0.73 \\
\hline \multirow{3}{*}{1400} & \multirow{2}{*}{0.2} & 25 & 2.41 & 1.64 & 0.68 \\
\cline { 3 - 6 } & & 50 & 2.71 & 1.71 & 0.63 \\
\cline { 3 - 6 } & \multirow{2}{*}{0.4} & 25 & 3.02 & 1.78 & 0.59 \\
\cline { 3 - 6 } & & 50 & 3.48 & 1.95 & 0.56 \\
\hline \multicolumn{6}{|c|}{ Average } & 0.56 \\
\hline
\end{tabular}

Overall, installing auxiliary lanes at weaving areas can significantly reduce traffic conflicts rate as opposed to the cases without auxiliary lanes.

\subsection{Safety Impacts with geographic conditions}

\subsubsection{Lane number of mainline}

Traffic conflict rate and TCMFs when $L_{s}$ is $200 \mathrm{~m}, R_{w}$ is 0.2 and $R_{H G V}$ is $25 \%$ are shown in Fig.3 5. TCMFs values get lower when there are fewer lanes in mainline, in other words, the safety impact is more effective. Because when lanes in mainline are fewer, there is a more complicated situation that through and weaving vehicles mixing in the same line. For the lack of space for changing speed and waiting for a safety gap, more conflicts will occur. So when there are fewer lanes in main line of weaving areas, auxiliary lanes can be taken into consideration.

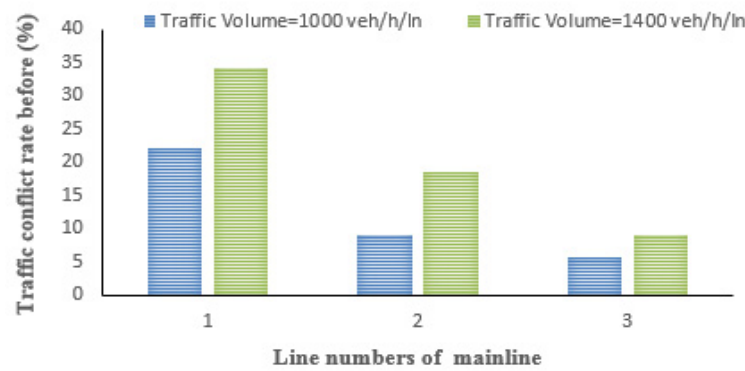

Figure 3. Traffic conflict rate before implementing ALs

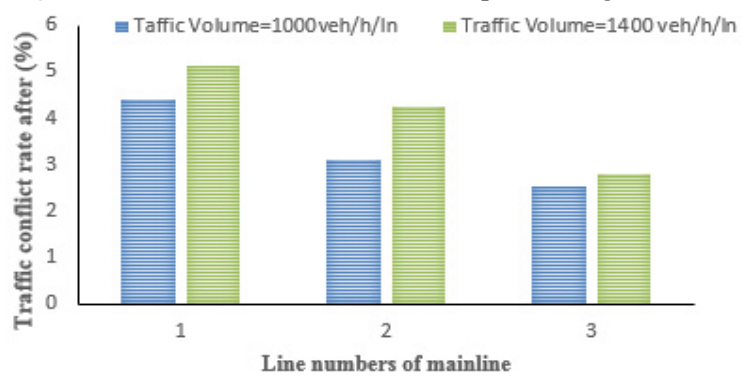

Figure 4. Traffic conflict rate after implementing ALs

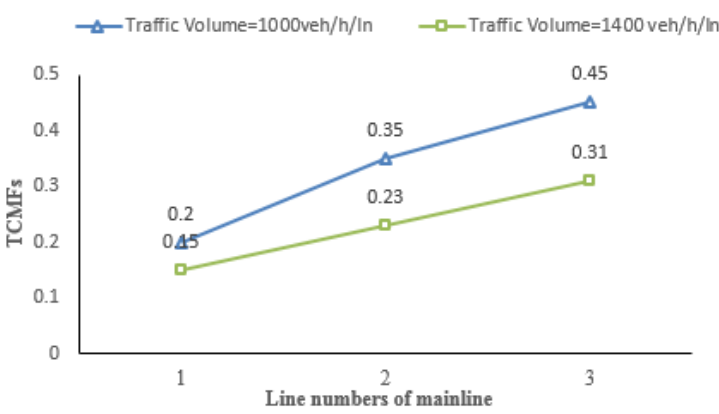

Figure 5. Relation between line numbers of mainline and TCMF

\subsubsection{Ramp spacing}

TCMFs values get lower when the ramp spacing are shorter (Fig.6). Because when the length between onramp and off-ramp is short, there are not enough time and space for those weaving vehicles to perform a series of behaviors including acceleration/deceleration, lanechanging, etc. Large differences of vehicle speeds can lead to disturbance and crash risk, especially when the speed of vehicles on freeway are high. The merge and diverge influence areas are normally defined at a length of $450 \mathrm{~m}$ in the HCM $(2000,2010)$, so when ramp spacing is shorter than this value, it's essential to design ALs. This is particularly true for weaving areas at cloverleaf type interchanges. ALs can be a cost effective method to increase capacity and safety particularly in cases where the facility experiences high entrance and exits from adjacent interchanges. The threshold value can be smaller when traffic volume and weaving volume are high.

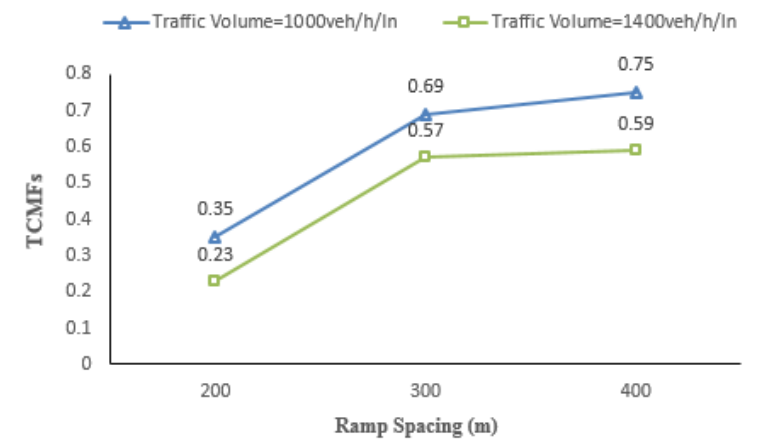

Figure 6. Relation between ramp spacing and TCMF

\subsection{Safety Impacts with traffic conditions}

\subsubsection{Traffic volume}

The reduction of traffic conflicts with ALs could be especially significant when high traffic volume, especially weaving volumes were present. (Fig.7) (e.g., with a through volume of $1400 \mathrm{veh} / \mathrm{h} / \mathrm{h}$ and weaving ratio of 0.4 ). Weaving is the most complicated behaviour in weaving areas, it consists of groups of vehicles performing speed-changing, lane-changing and other actions. Besides, driver factors is much more complicated and could also be important in this situation. ALs can provide sufficient space for those weaving vehicles and could also be taken as a buffer zone for those careless drivers.

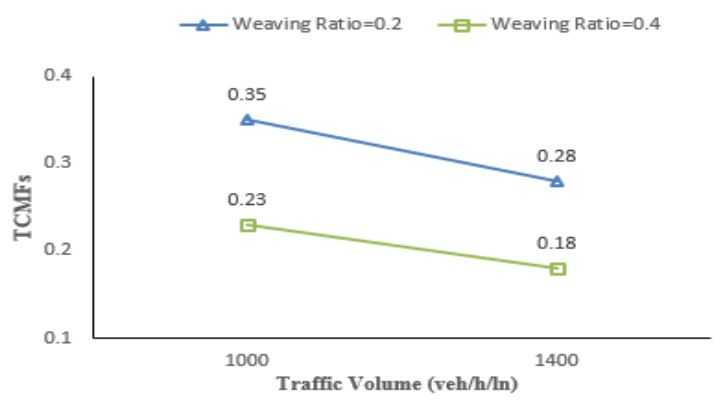

Figure 7. Relation between traffic volume and TCMF 


\subsubsection{Percentage of HGV}

TCMFs values get lower when the percentage of HGV are higher.(Fig.8) Because the differences of speed, acceleration/deceleration and other characteristics between $\mathrm{HGV}$ and cars, $\mathrm{HGV}$ can form a blocking effect on lateral roads to cars lane-changing. So it can be a problem to have HGV mixed in traffic flow.

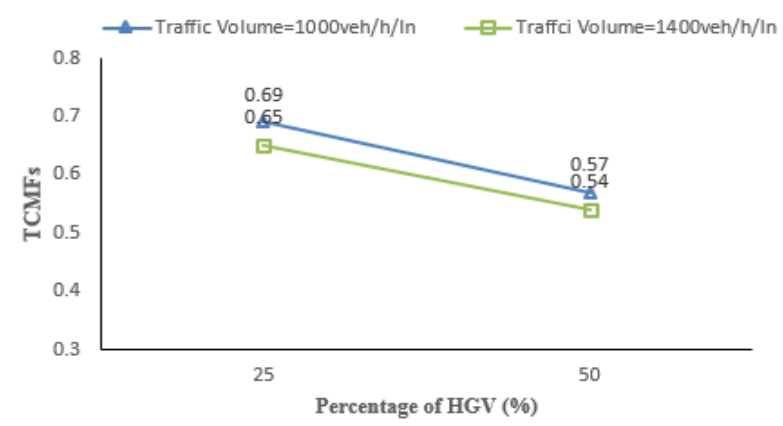

Figure 8. Relation between percentage of $\mathrm{HGV}$ and TCMF

\section{Conclusion}

This paper investigated the safety impacts of adding auxiliary lanes by analyzing the traffic conflicts derived from the traffic simulation studies. The results showed that:

- Adding auxiliary lanes can significantly reduce the ratio of traffic conflicts in freeway weaving areas.

- Safety influential factors considered in ALs design include geographic conditions, traffic conditions and other management conditions. In particular, this paper analyze the factors of ramp spacing, lane numbers of mainline, through volume, weaving ratio and percentage of HGV. The results show that these factors have great influence on safety impacts of ALs.

The findings can provide support to effective decision making with regards to constructing future auxiliary lanes in freeway interchange weaving areas.

\section{Acknowledgements}

This work is supported by the Fundamental Research Funds for the Central Universities and the Graduate Scientific Innovation Research Foundation of Jiangsu Province (KYLX16_0274). The authors also would like to thank the graduate research assistant at the School of Transportation at the Southeast University for their as sistance in field data collection.

\section{References}

1. American Association of State Highway and Transportation officials (AASHTO). A policy on geometric design of highways and streets. Washington D.C., (2004)

2. DoT, U.S. Manual on uniform traffic control devices (MUTCD). Federal Highway Administration, Washington, DC, (2003)

3. Japan Highway Public Corporation. Japan Highway Design Essentials. Shaanxi Travel \& Tourism Press, China, (1991).

4. Design Specification for Highway Alignment. Publication JTG D20-2006. Min istry of Transport of the People's Republic of China, (2006).

5. Guidelines for Design of Highway Grade-separated Intersections. Publication JTGT D21-2014. Ministry of Transport of the People's Republic of China, (2014).

6. Kuhn B, Balke K, Chaudhary N A, et al. Managed Lanes Strategies Feasible for Freeway Ramp Applications. (2007).

7. Hongjun Tian, Chengxu Wang, Yanhua Han, Applications of auxiliary lanes and collectordistributor lanes in interchanges. $\mathrm{Ji}$ Lin Transportation Technology. Vol 4, pp: 11-13. (2006)

8. Mergia W Y. Exploring factors contributing to injury severity at freeway merging and diverging areas. University of Dayton, (2010).

9. Sarhan M, Hassan Y, Abd El Halim A O. Safety performance of freeway sections and relation to length of speed-change lanes. Canadian Journal of Civil Engineering, Vol.35, No.5, pp:531-541, (2008)

10. Glad R W. Weave analysis and performance: The Washington state case study. (2001).

11. Qi Y, Chen X, Cheu R K, et al. Design and Scope of Impact of Auxiliary Lanes. (2014).

12. Transportation Research Board, National Research Council, Highway Capacity Manual. Washington, DC (2010).

13. PTV VISSIM User's Manual 5. 0. Planung Transport Verkehr AG, D-76131 Karlsruhe, Germany, 2007.

14. Gettman, D., L. Pu, T. Sayed, and S. G. Shelby. Surrogate Safety Assessment Model and Validation: Final Report. Publication FHWA-HRT-08-051. FHWA, U.S.Department of Transportation, 2008

15. Li S, Xiang Q, GU X, et al. The Types Division and Severity Threshold of Traffic Conflict on Freeway Interchange. MATEC Web of Conferences. EDP Sciences, Vol.81, No. 02006, (2016). 